\title{
Cidade literária, urbanismo arcaico: Brasília de Guimarães Rosa e João Cabral de Melo Neto
}

Luis Alberto Brandão Santos Universidade Federal de Minas Gerais

Aí estás, Brasília! E, como estás, pareces ave de asas abertas sobre a terra: vôo pousado para alçar-se, altivo!

N ão é difícil observar, nesse trecho da "Prece natalícia de Brasília", ${ }^{1}$ pronunciada pelo acadêmico Guilherme de Almeida no dia 21 de abril de 1960, a visão triunfalista que esteve na base do processo de planejamento e construção da nova capital. Concebida para ser um marco da modernização no Brasil, Brasília surge como signo de afirmação de uma nova era, como gesto de desafio, que pretende condensar e difundir a imagem de um Brasil-potência. Tratava-se de criar não apenas uma cidade, mas uma nova forma de organização social, nova cultura, nova sensibilidade: um homem novo. A empreitada arquitetônica, em geral restrita à interferência em espaços físicos já constituídos, se vê transformada em algo muito mais ambicioso: em atividade amplamente urbanística, entendida como a tentativa de arregimentação de todos os planos de uma sociedade humana.

${ }^{1}$ ALMEIDA, 1971. p. 214. 
Não é por acaso que Brasília é concebida como uma "capital aérea”, expressão utilizada, no Plano-Piloto, pelo próprio Lúcio Costa. ${ }^{2}$ Não se trata somente de uma referência a seu formato. Ao se construir uma cidade dotada de asas, conjugando o saber intuitivo do pássaro à mais avançada tecnologia aeronáutica, veicula-se um desejo específico e um determinado modo de olhar. O desejo das alturas, que é também o desejo da altivez. O desejo de se poder orbitar no vazio, em um espaço desprendido de referências, espaço irrestrito, propício à total autonomia de vôo. Espaço sem caminhos pré-traçados, no qual é o deslocamento que constitui a trilha. Buscando os elevados ares, encontra-se um não-espaço, a utopia de libertar-se das contingências para habitar o próprio espaço do desejo. E é desse não-espaço que se forja o olhar do urbanista-aeronauta: um olhar que vê sempre de cima, como um olho divino, que é capaz de mapear os territórios, de planejar suas formas ideais, de fundá-los como organismo, dotando-o de vida e leveza, içando-o ao alto com o seu sopro.

Irreverentemente, ou melhor, com uma irreverência que se considera plena inocência, o olho projeta-se na amplitude dos espaços abertos, infinitos, sem quaisquer obstáculos a seu movimento. Eis o olho do homem moderno, disposto a olhar como se fosse sempre pela primeira vez. Olho infantil, o mais adequado, segundo Baudelaire, para compreender a modernidade expressa pela cultura urbana: "A criança vê tudo como novidade: ela sempre está inebriada". ${ }^{3}$ Brasília foi planejada para inebriar-se com as alturas, para olhar com os olhos virgens de uma criança. Em outro trecho da "Prece" de Guilherme de Almeida, ressoa a louvação ao poder inconteste desse novíssimo olho:

Aí estás, Brasília do olhar de menina! Menina-dos-olhos olhando sem mágoa o passado e sem medo o Futuro, sem ver horizontes na terra e no céu porque eles recuam ao impacto impetuoso das tuas pupilas ${ }^{4}$

${ }^{2}$ COSTA, 1971. p. 139.

${ }^{3}$ BAUDELAIRE, 1996. p. 18.

${ }^{4}$ ALMEIDA, 1971. p. 214. 
A presença intensa da imagem do vôo e a constituição de um olhar infantil também podem ser observadas em dois contos do livro Primeiras estórias, de Guimarães Rosa, cuja primeira edição foi publicada em 1962. Os contos "As margens da alegria" e "Os cimos",, abertura e conclusão do livro, têm como protagonista um menino - significativamente denominado "O Menino" - e narram, ambos, viagens ao "lugar onde se construía a grande cidade". ${ }^{6} \mathrm{O}$ início do primeiro conto, quando o menino embarca no avião "especial", "da Companhia”, é marcado por uma intensa sensação de plenitude. "Era uma viagem inventada no feliz: para ele, produzia-se em caso de sonho". O clima de deslumbramento é hiperbólico, contamina todas as pequenas ações:

Respondiam-lhe a todas as perguntas, até o piloto conversou com ele. O vôo ia ser pouco mais de duas horas.O menino fremia no acorçô, alegre de se rir para si, confortavelzinho, com um jeito de folha a cair. A vida podia às vezes raiar numa verdade extraordinária. Mesmo o afivelarem-lhe o cinto de segurança virava forte afago, de proteção, e logo novo senso de esperança: ao não-sabido, ao mais. Assim um crescer e desconter-se - certo como o ato de respirar o de fugir para o espaço em branco. O Menino. ${ }^{7}$

Todas as perspectivas se abrem. Todas as promessas estão prontas para serem cumpridas. Nada se opõe ao desejo. Ou melhor: o desejo nem chega a se manifestar, já que, nesse estado de infância absoluta, paradisíaca, qualquer possível demanda já foi, de antemão, atendida. "E as coisas vinham docemente de repente, seguindo harmonia prévia, benfazeja, em movimentos concordantes: as satisfações antes da consciência das necessidades". ${ }^{8}$ O olhar infantil, que absorve a verdade total, que capta a mais esfuziante luminosidade, pode, do alto, compreender o mundo como um mero conjunto de

\footnotetext{
${ }^{5}$ ROSA, 1988. p. 7-12 e 152-160.

${ }^{6}$ ROSA, 1988. p. 7.

${ }^{7}$ ROSA, 1988. p. 7.

${ }^{8}$ ROSA, 1988. p. 7.
} 
pontos em um mapa. Sua visão é imponentemente cartográfica: reduz, à sua perspectiva, as dimensões dos objetos observados. "Se homens, meninos, cavalos e bois - assim insetos?"'

A primeira parte do conto é toda marcada pela euforia da descoberta: "O Menino via, vislumbrava. Respirava muito. Ele queria poder ver ainda mais vívido - as novas tantas coisas - o que para os seus olhos se pronunciava". ${ }^{10}$ Este Menino maiúsculo é uma espécie de Adão, fundando um universo à medida que o nomeia. Seu olhar inaugural está sintetizado na figura de um peru, que aparece no quintal da casa de madeira, próximo à mata: um peru "imperial", "completo", "para sempre", ${ }^{11}$ símbolo explícito de potência. A grandiloqüência da percepção do Menino condiz com o espírito norteador da construção daquela cidade. Uma grande realização que surge do nada, como num passe de mágica. Como se a mesquinhez das regras da realidade tivesse sido burlada. Por isso o Menino podia sentir-se "nos ares". Por isso era possível afirmar: "Esta grande cidade ia ser a mais levantada do mundo". ${ }^{12}$

A segunda metade do conto, no entanto, coloca um fim nesse entusiasmo desmedido. O peru fora morto. O Menino agora penetra em um ambiente hostil no qual "tudo perdia a eternidade e a certeza”. A construção da cidade passa a ser percebida sob a ótica do cansaço extremo, como uma tarefa terrível, comandada pela tosca ação das máquinas: construção percebida como destruição. O Menino "descobria o possível de outras adversidades", e, então, "abaixava a cabecinha". ${ }^{13}$

Entretanto, o final do conto revela uma nova mudança, que transpõe os dois pólos até então apresentados: de um lado a plenitude, do outro o desgosto e o remorso. Surge um outro peru, menor. Mas

\footnotetext{
${ }^{9}$ ROSA, 1988. p. 8.

${ }^{10}$ ROSA, 1988. p. 8.

${ }^{11}$ ROSA, 1988. p. 8.

${ }^{12}$ ROSA, 1988. p. 9.

13 ROSA, 1988. p. 10.
} 
também surge a cabeça degolada do primeiro. A alegria se reconstitui, mas recortada pela perplexidade. O Menino é introduzido no reino da ambigüidade, dos sentimentos contraditórios: "O Menino se doía e se entusiasmava" ${ }^{14}$ Constata-se a impossibilidade de compreender a perversidade do mundo: o novo peru bica, com ódio, a outra cabeça. Não há mais a luminosidade irrestrita do princípio. "Trevava". ${ }^{15} \mathrm{O}$ vôo, agora, não é grandioso, mas o de um modesto vagalume. O olhar é levado a se contentar com uma luz efêmera e intermitente.

\section{Poética arquitetural}

Há muitos pontos comuns entre o pensamento modernizador que fundamentou a concepção e a construção de Brasília e as opções estéticas que alicerçam a obra de João Cabral de Melo Neto. Pode-se citar, como algumas das linhas mestras da poética cabralina, a busca de racionalidade concretista, o planejamento minucioso das formas cuja autonomia é perseguida, em detrimento do subjetivismo e da ornamentação, a recusa da tradição vigente através da adoção de uma postura que considera crítica e criação como operações indissociáveis. Sobretudo, há o fascínio pela possibilidade de transplantar, para a poesia, o caráter construtivista da arquitetura. O próprio João Cabral enfatiza a grande influência exercida por nomes como Lincoln Pizzie, arquiteto, Joaquim Cardozo, calculista de Brasília e de outros projetos de Niemeyer e, fundamentalmente, Le Corbusier: "Para mim, a poesia é uma construção, como uma casa. Isso eu aprendi com Le Corbusier. A poesia é uma composição. Quando digo composição, quero dizer uma coisa construída, planejada - de fora para dentro". ${ }^{16}$

A eleição da concretude do "fora" como vetor determinante do processo poético equivale à recusa do império da subjetividade

\footnotetext{
${ }^{14}$ ROSA, 1988. p. 11.

${ }^{15}$ ROSA, 1988. p. 12.

${ }^{16}$ MELO NETO, 1996. p. 21.
} 
sustentado pela força da tradição romântica. Trata-se, assim, de esvaziar o "dentro" para que a poesia se construa a partir de um território vazio. De maneira similar ao movimento de quem almeja "edificar do nada"17 uma cidade, como ocorre com o urbanista moderno, o gesto do poeta é o gesto daqueles que "têm um vazio a preencher". ${ }^{18}$

Através da identificação entre poeta e arquiteto, constata-se, na obra de João Cabral de Melo Neto, o endosso do caráter utópico - tipicamente modernista - que está na base da concepção de Brasília. Tal concepção é marcada pela grandiloqüência das intenções, pelo "caráter monumental" do empreendimento. Nas palavras de Lúcio Costa: "monumental não no sentido de ostentação, mas no sentido da expressão palpável, por assim dizer, consciente, daquilo que vale e significa". ${ }^{19}$ Autoconsciência e racionalidade utópicas que ecoam com nitidez em versos como os do poema "Fábula de um arquiteto". ${ }^{20}$

O arquiteto: o que abre para o homem

(tudo se sanearia desde casas abertas)

portas por-onde, jamais portas-contra;

por onde, livres: ar luz razão certa.

Notável em João Cabral é que o fato de endossar o potencial utópico vislumbrado na ação do arquiteto não pressupõe o abandono de uma visão crítica dos riscos dessa ação. No mesmo poema, chama-se atenção para a hipótese de que a arquitetura possa vir a "refechar o homem":

Onde vãos de abrir, ele foi amurando opacos de fechar; onde vidro, concreto; até refechar o homem: na capela útero, com confortos de matriz, outra vez feto.

\footnotetext{
${ }_{17}^{17}$ PEDROSA, 1981. p. 352.

${ }^{18}$ MELO NETO, 1996. p. 21.

${ }^{19}$ COSTA, 1971. p. 124-125.

${ }^{20}$ MELO NETO, 1994. p. 346.
} 
O ímpeto civilizador não abole a ameaça de retorno a um estágio primitivo. A lucidez obstinada pode se contaminar pela indolência sombria. A racionalidade não é necessariamente antídoto para o misticismo. A virilidade que abre pode se converter no introjetar feminino. O progresso descobre seu caráter regressivo.

\section{Vôo parado}

Retomando a obra de Rosa, pode-se dizer que o conto "Os cimos" é, de certa forma, uma imagem invertida de "As margens da alegria". A situação inicial é a mesma: o vôo do Menino para a Brasília em construção. Entretanto, ao contrário da efusividade inicial do primeiro conto, a sensação é a de um indisfarçável mal-estar, associado ao sofrimento: "Entrara aturdido no avião, a esmo tropeçante, enrolava-o de por dentro um estufo como cansaço; fingia apenas que sorria, quando lhe falavam. Sabia que a Mãe estava doente". ${ }^{21}$ O olho não se deslumbra mais com a possibilidade de ver tudo, de absorver a luminosidade plena: "A gente devia poder parar de estar tão acordado, quando precisasse, e adormecer seguro, salvo. Mas não dava conta. Tinha de tornar a abrir demais os olhos, às nuvens que ensaiavam esculturas efêmeras". A imagem do vôo deixou de ser gloriosa e radiante, de indicar um movimento orgulhosamente progressivo. O vôo, agora, é estático, ou mesmo regressivo: "O avião não cessava de atravessar a claridade enorme, ele voava o vôo - que parecia estar parado. Mas no ar passavam peixes negros, decerto para lá daquelas nuvens: lombos e garras. $\mathrm{O}$ menino sofria sofreado. $\mathrm{O}$ avião então estivesse parado voando - e voltando para trás, mais, e ele junto com a Mãe". ${ }^{22}$

O frescor do olho infantil já está comprometido pela adversidade e pela nostalgia de algo que se perdeu. O Menino não é mais tão substantivo, concentrado apenas em sua própria mirada. Ele se descentra, percebe-se no ato de incorporar olhares alheios, "como

\footnotetext{
${ }^{21}$ ROSA, 1988. p. 152.

${ }^{22}$ ROSA, 1988. p. 153.
} 
assistir às certezas lembradas por um outro; era que nem uma espécie de cinema de desconhecidos pensamentos; feito ele estivesse podendo copiar no espírito idéias de gente muito grande". ${ }^{23}$ O Menino envelhece.

No decorrer do conto, redescobre-se o encanto, reconquistado através do vôo de um tucano, "suspenso esplendentemente". A imagem do vôo recupera um sentido de plenitude de luz e de certeza: "Toda a luz era dele, que borrifava-a de seus coloridos". ${ }^{24}$ No entanto, constatase em seguida que o vôo do tucano é, na verdade, descontínuo; não é movimento puro, mas também estaticidade, não-vôo, "feito se, a cada parte e pedacinho de seu vôo, ele ficasse parado, no trecho e impossivelzinho do ponto, nem no ar - por agora, sem fim e sempre". ${ }^{25}$ O conto transforma-se em um jogo de ganhos e perdas. Perde-se o boneco, acha-se o seu chapéu anteriormente perdido. Ganha-se a desejada recuperação da saúde da mãe, arca-se com a consciência de que aqueles são "dias quadriculados". ${ }^{26}$ Ganha-se o encanto, mas "depois do encanto, a gente entrava no vulgar inteiro do dia". ${ }^{27}$ No final, afastando-se de Brasília, o olhar do Menino não vê mais a totalidade da paisagem a seus pés, subordinada aos mapas. A paisagem, agora, está "fora das molduras". ${ }^{28} \mathrm{O}$ vôo, cercado de enigmas, e não mais de verdades, não se conclui, é um vôo que ainda não chegou.

Superpondo, à imagem de Brasília como "cidade a mais levantada" e cidade aérea, uma gama de imagens de vôo que vão da mobilidade ao estático, da luz total às trevas, do pensamento infantil ao envelhecido, da perspectiva de visão superior ao olho que não vê, Guimarães Rosa explora as ambigüidades que estão no cerne do imaginário brasileiro relativo à modernização urbana.

\footnotetext{
${ }^{23}$ ROSA, 1988. p. 154.

${ }^{24}$ ROSA, 1988. p. 155.

${ }^{25}$ ROSA, 1988. p. 156.

${ }^{26}$ ROSA, 1988. p. 158.

${ }^{27}$ ROSA, 1988. p. 157.

${ }^{28}$ ROSA, 1988. p. 159.
} 
Coloca-se em discussão a crença na viabilidade de um projeto civilizatório baseado na grandiloqüência de intervenções estatais. A Brasília literária surge como orgulho mas também como vítima de uma suposta racionalidade urbanizadora. Edificar, colocar em prática um projeto utópico envolve, inexoravelmente, a perda da inocência, o confronto com fatores que corroem os ideais, ou, ainda, que revelam a face autoritária escondida sob a máscara das boas intenções. Nesse sentido, Rosa se inscreve na mesma perspectiva de outros escritores brasileiros, como o próprio João Cabral de Melo Neto, que enxerga, nos palácios de Brasília, casas-grandes de engenho, ${ }^{29}$ ou Clarice Lispector, quando observa que, apesar de ter sido construída sem um lugar para os ratos, Brasília acaba sendo por eles invadida. ${ }^{30}$

$\mathrm{Na}$ direção contrária aos discursos triunfalistas - como o de André Malraux, que detecta, em Brasília, a possibilidade de "pôr a arquitetura ao serviço da Nação, de restituir-lhe parte da alma, que perdera" ${ }^{1}$-, as imagens literárias esboçam o vôo extremo da modernidade não apenas segundo seu poder de propulsão, sua velocidade, mas também segundo seus vetores de paralisia ou retenção, seus inevitáveis atrasos. Apontam para o fato de que reconstituir a alma ideal da nação é impossível, e que essa alma só pode mesmo reconhecer-se como perda.

\section{Porosidade do concreto}

Se compreendemos Brasília como uma espécie de absolutização do gesto modernista - o moderno levado a seu limiar -, encontramos nela um campo privilegiado para o reconhecimento das contradições de tal gesto. É na cidade mais tipicamente moderna que as dissonâncias do moderno se expõem na sua máxima intensidade. E a obra de João Cabral se alimenta dessas dissonâncias para propor

\footnotetext{
${ }^{29}$ MELO NETO, 1994. p. 399.

${ }^{30}$ Cf. LISPECTOR, 1975.

${ }^{31}$ MALRAUX, 1969. p. 20.
} 
uma reflexão a respeito do modo como se constitui a cultura brasileira. É possível detectar, acompanhando a perspectiva poética sugerida por suas imagens de Brasília, a principal linha que compõe um retrato crítico do Brasil:

No cimento duro, de aço e de cimento, Brasília enxertou-se, e guarda vivo, esse poroso quase carnal da alvenaria da casa de fazenda do Brasil antigo. ${ }^{32}$

O que se realça é que nas pretensas concretude e coesão do projeto modernizador está infiltrada a porosidade resistente da tradição colonial como traço básico da cultura brasileira. Nos interstícios da sofisticação industrial urbana, os resíduos irremovíveis do primitivismo agrário e escravocrata. É verdade que, no Plano-Piloto, o próprio Lúcio Costa já se referira à construção de Brasília como um "ato desbravador, nos moldes da tradição colonial". ${ }^{33}$ Tal afirmativa deveria, a princípio, soar estranha ao ímpeto de modernização - que se sustenta, obviamente, pela negação do passado. No entanto, quando se associa a ação de colonizar à de desbravar, cultiva-se uma visão heróica da colonização, o que corresponde a dizer que a colonização é pensada da perspectiva do colonizador. O desenho da aeronave - traçado básico de Brasília e reconstituição moderna da Cruz de Malta içada nas caravelas portuguesas - atualiza o ímpeto de expansão do mundo, de domínio de novos territórios. Gloriosa, a expansão acredita justificar-se por si mesma, por sua própria inexorabilidade.

O que se encontra na poesia de João Cabral de Melo Neto não é o apagamento da interface conflituosa colonizador-colonizado, mas, exatamente, a exploração de tal interface. Dessa maneira, é possível fazer vir à tona o caráter profundamente arcaizante do intuito modernizador. É possível enxergar Brasília como uma cidade arcaica, como a mais arcaica das cidades. Cidade onde os palácios

\footnotetext{
32 MELO NETO, 1994. p. 347.

${ }^{33}$ COSTA, 1971. p. 123.
} 
são "casas-grandes", ${ }^{34}$ sintetizando a repetição das estratégias de dominação do passado colonial.

No poema "À Brasília de Oscar Niemeyer", ${ }^{35}$ o "espraiamento da alma" visado pelo olho modernizador é viabilizado pela horizontalidade dos espaços. Contudo, se o olho se lança a partir das novas edificações - que são "horizontais, escancaradas", mas não deixam de ser "casas-grandes de engenho" -, as imagens por ele produzidas são marcadas por uma ambigüidade perversa, seja na indisfarçável retórica de seu tom nacionalista, seja no caráter impositivo de sua pretensão pedagógica:

Eis casas-grandes de engenho, horizontais, escancaradas, onde se existe em extensão e a alma todoaberta se espraia.

Não se sabe é se o arquiteto as quis símbolos ou ginástica: símbolos do que chamou Vinícius "imensos limites da pátria" ou ginástica, para ensinar quem for viver naquelas salas um deixar-se, um deixar viver de alma arejada, não fanática.

\footnotetext{
${ }^{34}$ MELO NETO, 1994. p. 348.

35 MELO NETO, 1994. p. 399.
} 


\section{Referências Bibliográficas}

ALMEIDA, Guilherme de. Prece natalícia de Brasília. In: SILVA, Ernesto. História de Brasília. Brasília: Coordenada, 1971.

BAUDELAIRE, Charles. Sobre a modernidade. Trad. Teixeira Coelho. São Paulo: Paz e Terra, 1996.

COSTA, Lúcio. Plano-Piloto de Brasília. In: SILVA, Ernesto. História de Brasília. Brasília: Coordenada, 1971.

LISPECTOR, Clarice. Visão do esplendor. Rio de Janeiro: Francisco Alves, 1975.

MALRAUX, André. Brasília na palavra de André Malraux. Rio de Janeiro: Presidência de República - Serviço de Documentação, 1959.

MELO NETO, João Cabral de. Considerações do poeta em vigília. Cadernos de literatura brasileira. São Paulo: Instituto Moreira Salles, n. 1, mar. 1996. Entrevista. MELO NETO, João Cabral de. Obra completa. Rio de Janeiro: Nova Aguilar, 1994. PEDROSA, Mário. Dos murais de Portinari aos espaços de Brasília. São Paulo: Perspectiva, 1984.

ROSA, João Guimarães. Primeiras estórias. 23. ed. Rio de Janeiro: Nova Fronteira, 1988.

\section{Resumo}

O objetivo deste ensaio é investigar, através da análise dos contos "As margens da alegria" e "Os cimos", do livro Primeiras estórias, de Guimarães Rosa, e de alguns poemas de João Cabral de Melo Neto, o modo como esses autores abordam as ambigüidades do processo de modernização urbana no Brasil, ao elegerem a cidade de Brasília como ponto de partida para uma reflexão sobre as especificidades da interface moderno/arcaico na cultura brasileira.

\section{Abstract}

The aim of this essay is to investigate, through the analysis of the short stories "As margens da alegria" and "Os cimos", from Primeiras estórias, by Guimarães Rosa, and of some João Cabral de Melo Neto's poems, how these authors approach urban modernization process ambiguities in Brazil, by choosing the city of Brasília as a point of departure to a reflection on brazilian culture modern/archaic interface specificities. 